\title{
$\gamma$-Tocopherol Attenuates Ozone-induced Exacerbation of Allergic Rhinosinusitis in Rats
}

\author{
James G. Wagner ${ }^{1}$, Jack R. Harkema ${ }^{1}$, Qing Jiang ${ }^{2}$, Beate Illek ${ }^{3}$, Bruce N. Ames ${ }^{3}$, and \\ David B. Peden 4 \\ ${ }^{1}$ Department of Pathobiology and Diagnostic Investigation, Michigan State University, East \\ Lansing, MI 48824, USA \\ ${ }^{2}$ Department of Foods and Nutrition, Purdue University, West Lafayette, IN 47907, USA \\ ${ }^{3}$ Children's Hospital of Oakland Research Institute, Oakland, CA 94609, USA \\ ${ }^{4}$ Center for Environmental Medicine, Asthma, and Lung Biology, University of North Carolina, \\ Chapel Hill, NC 27599, USA
}

\begin{abstract}
Compared to healthy subjects, individuals with allergic airway disease (e.g., asthma, allergic rhinitis) have enhanced inflammatory responses to inhaled ozone. We created a rodent model of ozone-enhanced allergic nasal responses in Brown Norway rats to test the therapeutic effects of the dietary supplement g-tocopherol $(\gamma \mathrm{T})$. Ovalbumin (OVA)-sensitized rats were intranasally challenged with $0 \%$ or $0.5 \%$ OVA (in saline) on Days 1 and 2, and then exposed to 0 or $1 \mathrm{ppm}$ ozone (eight hours/day) on Days 4 and 5. Rats were also given 0 or $100 \mathrm{mg} / \mathrm{kg} \gamma \mathrm{T}$ (p.o., in corn oil) on days 2 through 5, beginning twelve hours after the last OVA challenge. On Day 6, nasal tissues were collected for histological evaluation and mor-phometric analyses of intraepithelial mucosubstances (IM) and eosinophilic inflammation. Nasal septal tissue was microdissected and analyzed by reverse transcriptase polymerase chain reaction (RT-PCR) for mucin glycoprotein 5AC (MUC5AC) expression levels. Histological analysis revealed mild to moderate eosinophil influx in the mucosa lining the nasal airways and maxillary sinus of OVA-challenged rats (eosinophilic rhinosinusitis). Ozone exposure of allergic rats further increased eosinophils in the maxillary sinus $(400 \%)$, nasolacrimal duct $(250 \%)$, and proximal midseptum (150\%). Storage of intraepithelial mucosubstances (IM) was not significantly affected by OVA challenge in filtered air-exposed rats, but it was increased by ozone in the septum (45\%) and maxillary sinus (55\%) of allergic compared to control rats. Treatment with $\gamma \mathrm{T}$ attenuated the ozone/ OVA-induced synergistic increases in IM and mucosal eosinophils in both nasal and paranasal airways. $\gamma$ Tocopherol also blocked OVA and ozone-induced MUC5AC gene expression. Together, these data describe a unique model of ozone enhancement of allergic rhinosinusitis and the novel
\end{abstract}

Copyright $@ 2009$ by The Author(s)

For reprints and permissions queries, please visit SAGE's Web site at http://www.sagepub.com/journalsPermissions.nav

Address correspondence to Dr. James G. Wagner, 211 Food Safety and Toxicology Bldg, Department of Pathobiology and Diagnostic Investigation, Michigan State University, East Lansing, MI, 48824; wagnerja@msu.edu.

Competing interests: The authors have not declared any competing interests. 
therapeutic efficacy of a common supplement, $\gamma \mathrm{T}$, to inhibit ozone exacerbation of allergic airway responses.

\section{Keywords}

animal models; respiratory system; pathobiology; lung; inhalation

\section{Introduction}

Individuals with allergic airways disease are particularly sensitive to the adverse effects of ozone exposure. Increases in ambient ozone levels are associated with emergency room visits by asthmatic patients (Ko et al. 2007) and with increased use of asthma medication (Gent et al. 2003; Millstein et al. 2004). Nasal inflammation and adverse symptoms are reported in both healthy subjects (Kopp et al. 1999) and asthmatic patients with allergic rhinitis (Hiltermann et al. 1997) in response to episodic increases in ambient ozone concentrations.

Using a rodent model of allergic rhinitis, we have demonstrated that ozone exposure enhances allergen-induced mucous cell metaplasia (MCM) in both the transitional and respiratory epithelium of nasal airways (Wagner, Hotchkiss, and Harkema 2002). We have also described the temporal and spatial dependence of eosinophils with these epithelial alterations, although the mechanism by which ozone enhances allergic MCM and the role of eosinophils is not fully known. Acute exposure to ozone causes nasal epithelial and inflammatory responses in laboratory animals (Nikasinovic, Momas, and Seta 2003) and induces epithelial hyperplasia and MCM in the transitional and respiratory epithelium of both rats (Harkema et al. 1989) and monkeys. Neutrophil influx is required for the rapid induction of MCM by ozone, suggesting a critical role for acute inflammation in this process (Wagner, Hotchkiss, and Harkema 2001; Wagner et al. 2001).

Among the potential mechanisms contributing to airway pathobiology of allergic airway disease is an imbalance of oxidants and antioxidants. In allergic airway disease, antioxidants such as vitamins $\mathrm{E}$ (a-tocopherol; $\mathrm{aT}$ ) and $\mathrm{C}$ (ascorbic acid) are decreased in airway lining fluids, whereas the oxidized form of glutathione is increased in this fluid compartment (Kelly et al. 1999; Kongerud et al. 2003; Ochs-Balcom et al. 2006). These decrements in airway antioxidant defenses could increase the sensitivity of allergic persons to acute ozone exposure. In a study in Mexico City, ozone-induced nasal lesions and oxidative DNA damage are more prevalent in children diagnosed with asthma (Calderon-Garciduenas et al. 1999; Fortoul et al. 2003), and supplementation with a-tocopherol and ascorbate prevents ozone-induced nasal inflammatory responses in allergic children (Sienra-Monge et al. 2004). These studies support the hypothesis that therapeutic antioxidants likely limit the activity of environmental oxidants and prevent exacerbations of upper airway symptoms by ozone.

We have previously demonstrated that $\gamma$-tocopherol $(\gamma \mathrm{T})$, the major form of vitamin $\mathrm{E}$ in U.S. diets, has a number of anti-inflammatory actions, including blocking the production of tumor necrosis factor-a (TNFa), nitric oxide, and eicosanoid production during systemic nonallergic inflammatory challenge of laboratory rodents (Jiang and Ames 2003). Although 
dietary guidelines for vitamin $\mathrm{E}$ are based on $\mathrm{aT}$, several studies demonstrate that $\gamma \mathrm{T}$ is more effective at trapping electro-philes such as reactive nitrogen species (Christen et al. 1997; Cooney et al. 1993), inhibiting cycoloxygenase and inflammatory eicosanoid production (Jiang et al. 2000), and overall, providing a broader anti-inflammatory profile than aT (Jiang et al. 2001). With regard to allergic airways disease, many intervention studies with aT supplements have failed to protect from adverse airway responses in both humans and laboratory animals (Pearson et al. 2004; Shahar, Hassoun, and Pollack 2004; Suchankova et al. 2006), whereas dietary $\gamma \mathrm{T}$ intake has been negatively associated with allergic sensitization (Kompauer et al. 2006). We have recently reported in detail that $\gamma \mathrm{T}$ supplementation in allergic rodents can block ozone enhancement of allergic responses in the lung, specifically pulmonary inflammation and corresponding increases in airway mucus and cytokine production (Wagner et al. 2008).

In the present study, we extended our observations in this animal model of ozone exacerbation of allergic rhinosinusitis and tested the hypothesis that $\gamma \mathrm{T}$ will inhibit pollutant- and allergen-induced epithelial and inflammatory responses in upper airways. Our results describe both the therapeutic effects of $\gamma \mathrm{T}$, as well as the unique interaction of ozone and allergen in paranasal airways that may be important for understanding human sensitivity to oxidant air pollutants.

\section{Materials and Methods}

\section{Animals}

Fifty-six male Brown Norway rats (Harlan, Indianapolis, IN), ten to twelve weeks of age, were randomly assigned to one of eight experimental groups ( $n=7 /$ group). Rats were free of pathogens and respiratory disease (based on health and pathology reports by the supplier) and were used in accordance with guidelines set forth by the All-University Committee on Animal Use and Care at Michigan State University. Animals were housed two per cage in polycarbonate boxes on aspen chip bedding, covered with filter lids, and they had free access to tap water and food (Tek Lad 22/5 Rodent Diet W 8649, Harlan Sprague Dawley, Indianapolis, IN, USA). During the inhalation portion of the study, rats were housed individually in rack-mounted stainless steel wire cages in Hazelton whole-body inhalation exposure chambers (HC-100, Lab Products, Maywood, NJ, USA). During ozone exposure, food was removed, but water was available.

\section{$\gamma$-Tocopherol}

d-gamma-tocopherol ( $\gamma \mathrm{T}$; R,R,R naturally occurring, 96\% pure by high performance liquid chromatography [HPLC] and nuclear magnetic resonance [NMR] analyses) was obtained from Yasoo Health, Inc. (Johnson City, TN, USA). Stock and diluted preparations were kept under nitrogen at $4{ }^{\circ} \mathrm{C}$ and contained no other tocopherols/tocotrienols or oxidation products, as confirmed by HPLC. Prior to treatment protocols, $\gamma \mathrm{T}$ was diluted in tocopherolstripped corn oil (Dyets, Inc., Bethlehem, PA). 


\section{Ozone Exposure}

Ozone was generated with an OREC model O3V1-O ozonizer (Ozone Research and Equipment Corp., Phoenix, AZ, USA) using compressed air as a source of oxygen. Total airflow through the exposure chambers was $250 \mathrm{~L} /$ minute (fifteen chamber air changes per hour). The concentration of ozone within the chambers was monitored throughout the exposure using two Dasibi 1003 AH ambient air ozone monitors (Dasibi Environmental Corp., Glendale, CA, USA). Sampling probes were placed in the breathing zone of rats within the middle of the cage racks. The concentration of ozone during exposures was 0.994 $+0.012 \mathrm{ppm}$ (mean + standard error of the mean [SEM]) for ozone chambers and less than $0.02 \mathrm{ppm}$ for chambers receiving filtered air.

\section{Treatment and Exposure Protocols}

The time course for treatment protocols is summarized in Figure 1. On Day 1, rats were sensitized to chicken albumin (ovalbumin; OVA; Sigma Chemical Co., St. Louis, MO) by intraperitoneal injection with $2.5 \mathrm{~mL}$ sterile saline of a solution containing $1 \mathrm{mg}$ OVA prepared with $10 \mathrm{mg}$ alum (aluminum potassium sulfate), which acts as an adjuvant. Two weeks later, rats were challenged to OVA or saline for two consecutive days (i.e., Days 14 and 15) under light anesthesia (4\% halothane in oxygen) by intranasal instillation (IN) with $150 \mathrm{~mL}$ of $0 \%$ or $0.5 \%$ OVA in sterile injectable saline into each nasal passage $(300 \mathrm{~mL}$ total volume). Intranasal instillation (IN) challenge procedures were conducted between 10:00 and 11:00 AM each day.

Beginning eight hours after the last IN challenge, rats were administered by oral gavage with 0 or $100 \mathrm{mg} / \mathrm{kg}$ body weight $\gamma \mathrm{T}$ prepared in tocopherol-stripped corn oil. Treatment with $\gamma \mathrm{T}$ was repeated daily at 6:00 PM for four consecutive days (Days 15-18). Beginning on Day 17, animals were exposed to 0 or $1.0 \mathrm{ppm}$ ozone for eight hours per day (7:30 AM-3:30 PM) for two consecutive days (Days 17 and 18). Animals were euthanized and tissues were collected on Day 19.

\section{Necropsy, Lavage}

Collection and Tissue Preparation-Rats were anesthetized with sodium pentobarbital $(50 \mathrm{mg} / \mathrm{kg}$, i.p. injection), and a midline laparotomy was performed. Four $\mathrm{mL}$ of blood was drawn into a vacutainer for separation of plasma, and animals were exsanguinated by cutting the abdominal aorta. After death, the head was removed and cleaned of skin and fur. Heads were split open to the reveal the right nasal cavity by cutting just off the midsagittal plane using the natural fissure separating nasal from maxillary and premaxillary bones of the proximal skull. The epithelium on the exposed right aspect of the proximal nasal septum was then microdissected (between T1 and T2 in Figure 2) and placed in RNALater solution (Qiagen, Valencia, CA) and stored at $4{ }^{\circ} \mathrm{C}$ until RNA was isolated. The left nasal cavity was then flushed retrograde with $1 \mathrm{~mL}$ of neutral-buffered formalin and then immersed in a large volume of the same fixative for storage. Twenty-four hours later, the heads were decalcified in $13 \%$ formic acid for five days. After decalcification, three nasal sections were taken from the anterior nasal cavity by making perpendicular cuts to the hard palate at the level (1) immediately posterior to the upper incisors, (2) at the incisive papilla, and (3) at the second palatine ridge (Figure 2). This procedure results in three anatomically specific nasal profiles 
referred to here as $\mathrm{T} 1, \mathrm{~T} 2$, and $\mathrm{T} 3$ and provides proximal to distal samples for morphometric and histological analysis. Tissue blocks were embedded in paraffin, and 5 to $6 \mathrm{~mm}$ thick sections were cut from the anterior surfaces. Nasal sections were stained with hematoxylin and eosin (H\&E) for routine histology, with Alcian Blue (pH 2.5)/Peri-odic Acid-Schiff (AB/PAS) to detect intraepithelial mucosubstances (IM), or with May-Grunwald stain to detect mucosal eosinophils. Site-specific morphometry of IM and eosinophils was conducted for the epithelium and underlying mucosa lining the proximal nasal septum (T1), proximal and distal nasolacrimal duct (T2, T3), and the proximal and distal maxillary sinus(T2, T3) as depicted in Figure 2B.

Tocopherols-Plasma aT and $\gamma \mathrm{T}$ were extracted using a mixture of methanol/hexane $(2: 5, \mathrm{v} / \mathrm{v})$ in the presence of $0.8 \mathrm{mM}$ butylated hydroxytoluene (BHT). After brief centrifugation at $4{ }^{\circ} \mathrm{C}$, the top hexane layer was dried under $\mathrm{N}_{2}$ and the residue was resuspended in ethanol. Tocopherols were separated on a $150 \times 4.6 \mathrm{~mm}, 5 \mathrm{~mm}$ Supelcosil LC-18-DB column (Supelco, Bellefonte, PA, USA) and eluted with 95:5 (v/v) methanol/ $0.1 \mathrm{M}$ lithium acetate (final $25 \mathrm{mM}, \mathrm{pH} 4.75$ ) at a flow rate of $1.3 \mathrm{~mL} /$ minute. Tocopherols were monitored by coulometric detection (Model Coulochem II, ESA, Inc., Chelmsford, MA, USA) at 300 (upstream) and $500 \mathrm{mV}$ (downstream electrode) using a Model 5011 analytical cell.

Morphometry of Stored Intraepithelial Mucosubstances (IM)-To estimate the amount of intraepithelial mucosubstances (IM) in nasal airways, the volume density (Vs) of $\mathrm{AB} / \mathrm{PAS}$-stained mucosubstances was quantified using computerized image analysis and morphometric techniques in the respiratory epithelium lining the midseptum and the maxillary sinus. Briefly, the area of AB/PAS-stained mucosubstance was estimated by setting colorized thresholds to highlight only IM, and these areas were then automatically calculated using the public domain NIH Image program (written by Wayne Rasband, U.S. National Institutes of Health and available on the Internet at http://rsb.info.nih.gov/nihimage/). We define the midseptum for this purpose as the septal region that is between the tip of the nasoturbinate and the base of the maxilloturbinate (Harkema, Hotchkiss, and Henderson 1989). The entire perimeter of the maxillary sinus was evaluated. The length of the basal lamina underlying the surface epithelium was calculated from the contour length of the digitized image of the basal lamina. The volume of stored mucosubstances per unit of surface area of epithelial basal lamina was estimated using methods described previously (Harkema et al. 1987). The volume density (Vs) of intraepithelial mucosubstances is expressed as nanoliters of intraepithelial mucosub-stances per $\mathrm{mm}^{2}$ of basal lamina.

Morphometry of Tissue Eosinophil Numeric Density-The numeric density of eosinophils in the nasal mucosa lining the midseptum, maxillary sinus, and the proximal and distal aspects of the nasolacrimal ducts was determined by counting May-Grunwald-positive stained cells with distinct eosinophil morphology. The same sites were evaluated in the septum and sinus as described for IM, and the entire perimeter of the nasolacrimal duct was also evaluated. The length of the basal lamina was calculated from its contour length in a digitized image as described above, and the data are expressed as the number of eosi-nophils divided by the length of the underlying basal lamina. 
Real Time RT-PCR-Mucin glycoprotein 5AC (MUC5AC) is the primary secretory mucin in airway epithelium, and we have previously demonstrated ozone and allergeninduced expression of the MUC5AC gene that was associated with mucous cell metaplasia in the nasal septum (Wagner, Hotchkiss, and Harkema 2002). We therefore evaluated nasal expression of MUC5AC in the present study to determine if $\gamma \mathrm{T}$ would modulate both stored epithelial mucus and gene expression for the mucin protein in the same tissue. Total RNA from septal epithelium was extracted using the RNeasy Mini Kit (Qiagen) according to the manufacturer's instructions. The evaluation of relative expression levels of rat MUC5AC mRNA (Applied Biosystems, Foster City, CA USA) was performed by two-step RT-PCR using manufacturer protocols. Briefly, reverse transcription was performed using High Capacity cDNA Archive Kit (Applied Biosystems) reagents. Quantitative mRNA expression analysis was performed using an ABI PRISM 7900 HT Sequence Detection System at Michigan State University's Research Technology Support Facility using Taqman Gene Expression Assay reagents (Applied Biosystems). Relative gene expression was normalized to 18S. Data are expressed as fold-increase in MUC5AC mRNA expression compared to control animals, which was set at a value of 1 .

\section{Statistical Analysis}

Data are expressed as mean \pm standard error of the mean (SEM). Data were analyzed using a completely randomized analysis of variance. Multiple comparisons were made by the Student-Newman-Keuls post hoc test. Criterion for significance was taken to be $p<.05$.

\section{Results}

\section{Plasma Tocopherols}

Plasma $\gamma \mathrm{T}$ was unaffected by ozone exposure or allergen challenge regimens in control rats supplemented with $0 \mathrm{mg} / \mathrm{kg} \gamma \mathrm{T}$ but was increased in all groups four- to five-fold with a dose of $100 \mathrm{mg} / \mathrm{kg} \gamma \mathrm{T}$ (Table 1). No differences were detected between exposure or challenge groups given $\gamma \mathrm{T}$. Plasma aT was similar in all groups given $0 \mathrm{mg} / \mathrm{kg} \gamma \mathrm{T}$, with trends toward decreases in OVA-challenged rats. Allergic animals dosed with $100 \mathrm{mg} / \mathrm{kg} \gamma \mathrm{T}$ and exposed to filtered air had significantly less aT in plasma than saline-challenged, air-exposed rats.

\section{Histopathology}

Rats Intranasally Instilled with OVA and Exposed to Ozone-No exposure-related nasal lesions were present in control rats intranasally instilled with saline and exposed to filtered air. In contrast, OVA instillation induced a mild to moderate MCM or mucous cell hyperplasia/hypertrophy in the surface respiratory epithelium lining the proximal nasal airways (T1 and T2). This OVA-induced epithelial change, characterized by an increase in AB/PAS-stained mucous cells, was most conspicuous in the maxillary sinus (T2) and the proximal midseptum (T1) (Figure 3). These lesions were exacerbated by subsequent ozone exposure. Saline-instilled rats had a normal thin, ciliated, pseudostratified respiratory epithelium lining the maxillary sinus that contained no or only a few widely scattered ABA/ PAS-stained mucous goblet cells. In contrast, rats intranasally instilled with OVA had numerous $\mathrm{AB} / \mathrm{PAS}$-stained mucous cells (metaplastic change) that were increased in size and number after ozone exposure (Figure 3B). Although the ciliated respiratory epithelium 
lining the proximal nasal septum in saline-instilled control rats contained tall columnar mucous cells with intracytoplasmic AB/PAS-stained mucosubstances, the number and size of these mucus-secreting cells were increased by OVA instillation, and further increased after ozone exposures (mucous cell hyperplasia/hypertrophy; Figure 3E).

A mild to moderate inflammatory cell influx composed mainly of eosinophils and lesser numbers of small lymphocytes and neutrophils was present in the mucosa lining the nasal airway and maxillary sinus of OVA-instilled and ozone-exposed rats (eosinophilic rhinosinusitis). Interestingly, minimal inflammatory cell infiltration was present in OVAinstilled rats exposed only to filtered air. The eosinophilic influx in the OVA/ozone rats was most prominent in the subepithelial tissues (lamina propria) of the respiratory mucosa lining the proximal midseptum (T1, T2; Figure 4), the transitional mucosa lining the lateral wall (T1; Figure 5) and nasal turbi-nates (maxillo- and nasoturbinates; T1), the maxillary sinus (T3), and the nasolacrimal ducts (T1, T2; Figure 6).

Only rats exposed to ozone had minimal to mild epithelial hyperplasia of the transitional epithelium lining the proximal lateral meatus that was bordered in part by the lateral wall, maxilloturbinate, and lateral surface of the nasoturbinate in the T1 section. This hyperplastic epithelial change had a slightly greater severity in the OVA-instilled rats that were exposed to ozone.

Rats Intranasally Instilled with OVA, Exposed to Ozone, and Treated with $\gamma \mathrm{T}-$ In general, treatment with $\gamma$ T markedly attenuated the eosinophilic rhinosinusitis in OVAinstilled and ozone-exposed rats. This treatment-related effect was most evident by the reduction of eosinophils in the mucosa lining the proximal midseptum (Figure 4), lateral wall (Figure 5), maxillary sinus, and nasolacrimal duct (Figure 6). In addition, there was a noticeable attenuation of mucous cell hyperplasia/hypertrophy of the respiratory epithelium lining the maxillary sinus (Figure 3C) and the proximal midseptum (Figure 3F) in these OVA-instilled rodents exposed to ozone.

\section{Morphometry}

Eosinophilic Numeric Cell Density-Exposure to ozone caused a twofold increase in eosinophils in the mucosa lining the nasal septum in nonallergic rats (Figure 7A), and similar increases were induced by OVA challenge. In allergic rats exposed to ozone, eosinophils increased 2.5-fold compared to animals exposed to ozone alone or challenged with OVA alone. Treatment with $\gamma \mathrm{T}$ attenuated all exposure- and challenge-related increases in eosinophil accumulation in the septum.

In the maxillary sinus, ozone exposure or OVA challenge alone induced significant recruitment of eosinophils into the mucosa (1.5-fold increases compared to salinechallenged, air-exposed control rats; Figure 7B). Eosinophil recruitment was synergistically enhanced by at least four-fold when allergic rats were exposed to ozone. Supplementation with $\gamma \mathrm{T}$ completely blocked ozone-induced enhancement of sinus inflammation, but it had no effect on OVA-induced eosinophil accumulation. 
In both proximal and distal aspects of the nasolacrimal duct, ozone exposure or OVA challenge alone had no significant effect on eosinophil numbers in the ductal mucosa (Figures 7C and 7D). However, exposure of allergic rats to ozone caused eight-fold (proximal aspect) and five-fold (distal aspect) increases in the number of mucosal eosinophils. Treatment with $\gamma \mathrm{T}$ completely blocked the synergistic eosinophil response to ozone and OVA in both regions of the nasolacrimal duct.

Mucous Cell Metaplasia-Ozone exposure had no effect on intraepithelial mucosubstances (IM) in the midseptum or maxillary sinus of nonallergic control rats (Figure 8). Challenge with OVA in rats exposed to filtered air caused increased IM in the septum and proximal sinus that was significantly enhanced when allergic rats were exposed to ozone (Figures 8A and 8B). In distal aspects of the maxillary sinus, significant increases in IM were seen only in allergic rats exposed to ozone, which were 2.5 - and five-fold greater compared to the OVA-only or ozone-only groups, respectively (Figure 8C). Treatment with $\gamma \mathrm{T}$ attenuated IM increases in both the septum and sinus airways of ozone-exposed, allergic rats. However, the OVA-induced increases of IM in air-exposed rats were not affected by $\gamma \mathrm{T}$.

Mucin Gene Expression-Ozone exposure had no effect on MUC5AC expression in the nasal septum of nonallergic rats (Figure 9). Ovalbumin challenge induced a 2.5-fold increase in mucin gene expression compared to control animals. Exposure to ozone had no significant effect on OVA-induced gene expression compared to ozone exposure to nonallergic animals. In rats given $\gamma \mathrm{T}$, gene expression was attenuated in allergic rats, regardless of exposure.

\section{Discussion}

Clinical and epidemiological studies have demonstrated associations of ozone exposure with exacerbation of allergic responses in the upper airways (Kopp et al. 1999; Peden, Setzer, and Devlin 1995; Riediker et al. 2001). In the present study, we evaluated the effects of ozone exposure on nasal epithelial and inflammatory cell responses in an animal model of allergic rhinitis and sinusitis. Our results demonstrate for the first time in a rodent model (1) allergen-induced mucous cell metaplasia (MCM) in the maxillary sinus and (2) ozone enhancement of allergen-induced responses in both the maxillary sinus and the nasolacrimal duct. Inflammation in these two paranasal structures is associated with the morbidity of sinusitis and rhinoconjuctivitis. Furthermore these unique lesions were attenuated by $\gamma \mathrm{T}$, a vitamin $\mathrm{E}$ isoform with novel anti-inflammatory properties.

Using an allergen/ozone coexposure model, we have previously described ozone enhancement of allergic MCM in the respiratory epithelium of the nasal septum, among other site-specific lesions (Wagner, Hotchkiss, and Harkema 2002). In those studies, rats were challenged with allergen immediately after daily ozone exposures; thus, the nasal epithelium received these two inflammatory stimuli at more or less the same time. In the current protocol, we waited two days after intranasal allergen provocation before beginning ozone exposures; thus, exposure was to a nasal epithelium with pre-existing allergeninduced alterations (airway remodeling). Similar to our results from the coexposure 
protocol, we found increased MCM in the nasal septum of allergic rats after ozone exposure (Figure 3). However, we also observed a robust influx of eosinophils into the nasal mucosa that was not seen in the previous coexposure study, suggesting that ozone-induced recruitment of inflammatory cells might contribute to the increased production and storage of intraepithelial mucosubstances. We have documented such a dependence with neutrophils and ozone-induced MCM in nonallergic models (Wagner et al. 2001). In the current study, blockade of both eosinophil and mucous responses in ozone-exposed rats by supplementing with $\gamma \mathrm{T}$ suggests there may be a similar relationship for allergic MCM in nasal airways.

One of our most intriguing findings in the present study was the response to ozone and allergen in upper airways that was detected outside the main nasal cavity. Airway walls in the proximal and distal maxillary sinus had increased mucosub-stances and eosinophil influx in allergic rats (Figures 3, 7, and 8). We used rodent nasal diagrams (Mery et al. 1994) to identify the maxillary sinus duct that begins proximal to the ethmoid turbinbates and enters the skull where it opens into an enlarged paranasal sinus airway lined with respiratory epithelium that is totally enclosed within the bone. Similar to what we described in the septum, we detected a trend for ozone-induced enhancement of mucus and eosinophilic responses in proximal sinus airways. Furthermore, in distal aspects of the maxillary sinus at least $3 \mathrm{~mm}$ from the duct opening, we detected increased IM only in allergic rats exposed to ozone. That ozone can reach deep into low-flow regions of the paranasal sinus and induce mucous cell responses in allergic rats suggests that similar synergistic responses may occur in asymptomatic people with a history of allergic rhinitis and sinusitis. Previous work in our group demonstrated MCM in the maxillary sinus of F344 rats after twenty months of exposure to 0.5 or 1 ppm ozone (Harkema, Hotchkiss, and Griffith 1997). In those studies, the proximal sinus had IM increases five-fold greater and with more robust inflammation than what we observed in the present study with allergic rats exposed for two days to ozone. The airway epithelium lining the paranasal sinus normally has scant amounts of stored mucus, and the increases in response to acute ozone may precede even greater increases with chronic and intermittent allergen and ozone exposures.

We also found treatment-related changes in the nasolacrimal duct, which drains from the orbital socket and into the proximal nasal passages. In these sites, neither allergen nor ozone alone caused inflammation by itself, but the combination of the two created a robust influx of mucosal eosinophils greater than what was observed in the maxillary sinuses. Responses in proximal and distal regions of the duct were equally severe. It should be noted that the distal site that we evaluated is approximately $4 \mathrm{~mm}$ from the duct opening in the proximal nasal cavity and almost half the distance to the orbital socket. As such, it is tempting to speculate that ozone irritation of the ocular tissues might contribute to the downstream inflammation we found in the nasolacrimal duct. Increases in ambient ozone concentrations are associated with ocular irritation and enhancement of symptoms in allergic rhinoconjunctivitis patients (Riediker et al. 2001; Sanchez-Carrillo et al. 2003). Soluble inflammatory mediators such as IL-4 and TNFa are produced in conjunctiva of OVAinduced allergic Brown Norway rats (Fukushima et al. 2003) and may drain into the nasolacrimal duct and mediate the recruitment of eosinophils into the mucosal tissues surrounding this duct. We have not yet examined more distal aspects of the duct closer to the eye or in ocular tissues to determine the extent of inflammation. 
We have recently reported that ozone enhancement of allergic responses also occurs in pulmonary airways (Wagner et al. 2007). Consistent with our current findings, we found that $\gamma \mathrm{T}$ treatment attenuates pulmonary epithelial and inflammatory responses. In both the nose and the lung, $\gamma \mathrm{T}$ inhibited ozone-specific enhancement, but not the allergen-induced MCM. In the current study, we saw this same relationship for both MCM and eosinophilic influx in the septum and proximal sinus. This may be a consequence of the timing of $\gamma \mathrm{T}$ supplementation during allergic processes. Dosing with $\gamma \mathrm{T}$ began ten hours after the second of two intranasal allergen challenges, at a time when significant eosinophilic infiltrates are present and increased intraepithelial mucosubstances induced by allergen are already evident (Wagner, Hotchkiss, and Harkema 2002). On the other hand, two treatments of $\gamma \mathrm{T}$ had been given before the first ozone exposure, which is sufficient for plasma and lung content of $\gamma \mathrm{T}$ to be significantly elevated (Wagner et al. 2008). Although nasal $\gamma \mathrm{T}$ tissue levels were not determined in the current study to confirm an increase in bioavailability, this brief supplementation was apparently sufficient for $\gamma \mathrm{T}$ content in nasal airways to protect from acute oxidant or inflammatory stimuli initiated by ozone inhalation.

Antioxidant supplements have been used successfully in humans suffering from micronutrient malnutrition to limit the severity of ozone-induced airway responses. For example, when people with deficits in dietary ascorbate were put on a supplementation regimen with aT, vitamin $\mathrm{C}$, and vegetable juice, ozone-induced decrements in pulmonary function were less severe than in those receiving no supplementation (Samet et al. 2001). In asthmatic children with poor antioxidant nutrition, intervention with combinations of aT and vitamin $\mathrm{C}$ protected from nasal inflammatory responses during high ambient ozone episodes in Mexico City (Sienra-Monge et al. 2004). However, these studies are in contrast to a report by Mudway et al. (2006), in which acute ozone-induced lung function decrements and airway inflammation were unaffected in healthy, well-nourished subjects despite taking supplements with twice the concentrations of aT and vitamin $\mathrm{C}$ used in the two aforementioned studies. Taken together, these disparate outcomes suggest that interventions to protect from adverse ozone responses are useful only during antioxidant and micronutrient deficiency and that further supplementation provides no added benefits over adequate nutrition.

Results from animal studies also describe limitations in the efficacy of aT to protect from ozone- and allergen-induced airway responses. For example acute ozone exposure to $\mathrm{BALB} / \mathrm{c}$ mice causes preferential increases in $\gamma \mathrm{T}$, ascorbate, and uric acid in bronchoalveolar lavage fluid compared to changes in a $\mathrm{T}$ (Jang et al. 2005). In addition, chronic ozone exposures and studies with dietary restriction suggest pulmonary antioxidant adaptation is dependent on mobilization and increases of pulmonary ascorbic acid, with no effect on aT (Kari et al. 1997; Wiester et al. 1996). In rodents with allergic airways, high aT doses of over 300 times the minimum suggested dietary intake for rodents fails to reduce allergen-induced pulmonary lesions or airway hyperreactivity (Suchankova et al. 2006). By comparison, we recently demonstrated the comprehensive protections by $\gamma \mathrm{T}$ at similar doses against allergic responses in both upper and lower airways of rats (Wagner et al. 2008). We did not compare different vitamin $\mathrm{E}$ forms in our previous study; however, we have used a nonimmunogenic inflammation model to demonstrate that $\gamma \mathrm{T}$ is superior to a $\mathrm{T}$ in limiting inflammatory cell recruitment and cytokine production (Jiang and Ames 2003). These 
results in laboratory rodents suggest that the $\gamma$ isoform of vitamin E may play a relatively more important role in pulmonary anti-inflammatory defenses and might help explain the lack of efficacy for aT supplements in controlled human studies.

Supplementation with $\gamma \mathrm{T}$ might inhibit ozone-induced enhancement of allergic MCM via a number of antioxidant and anti-inflammatory pathways. Ozone is a strong oxidant with primary toxicity of epithelial cell injury and production of ozonated lipid mediators. Results from airway epithelial culture systems demonstrate a role for oxidative stress and reactive oxygen species in mucin gene expression and mucus production (Fischer and Voynow 2002; Shao and Nadel 2005). As such, $\gamma \mathrm{T}$ might be limiting the direct oxidative effects of ozone on epithelial cells to initiate pathways that lead to mucus production. It is notable that the metaplastic response to ozone occurred only in the allergic rats, suggesting that this allergen-remodeled epithelium was somehow compromised or sensitized after OVA challenge to respond with enhanced signals to produce more mucus. These enhanced signal pathways were not present or effective when animals were supplemented by $\gamma \mathrm{T}$.

Alternatively, the metaplastic response might be engendered by products from infiltrating inflammatory cells that were called into the nasal mucosa after ozone exposure. Potential eosinophil-derived products that can stimulate mucin gene expression and protein production include nitric oxide (Adler et al. 1995; Song et al. 2007), cysteinyl leukotrienes (cysLTs) (Shimizu et al. 2000; Vargaftig and Singer 2003), and interleukin-13 (Vargaftig and Singer 2003). $\gamma$-tocopherol is a highly efficient quencher of nitric oxide and peroxynitrite in vitro (Wolf 1997), and we have previously demonstrated lipoxygenase inhibition by $\gamma \mathrm{T}$ (Jiang and Ames 2003). Although $\gamma \mathrm{T}$ can block the activity of these mucusstimulating factors, the recruitment and accumulation of eosinophils were attenuated by $\gamma \mathrm{T}$, thereby removing the putative sources of these inflammagenic mediators. It is not clear from the present results whether the inhibition of mucous cell responses by $\gamma \mathrm{T}$ is due to direct effects on the epithelium, the inhibition of inflammatory cell recruitment, or both.

Ovalbumin-induced gene expression for the mucin glyco-protein MUC5AC was not enhanced after ozone exposure despite the increase in stored epithelial mucus in ozoneexposed, allergic rats (Figures 8A and 9). Furthermore, while supplementing rats with $\gamma \mathrm{T}$ suppressed gene expression, the increase in epithelial mucus was not affected in allergic rats. The apparent disconnect in intraepithelial mucus and gene expression may be explained by the analytic methods for each end point; histochemical staining with AB/PAS interacts with carbohydrate residues on the mucin glycoprotein surface, whereas RT-PCR reflects gene encoding the MUC5AC core protein. Further steps of translation and post-translation glycosylation of the protein are required to produce the mucin glyoprotein identified by AP/PAS staining of intraepithelial mucosubstances. We have previously demonstrated the temporal delay between mucin gene expression and the appearance of intraepithelial mucus in the rodent nose (Cho, Hotchkiss, and Harkema 1999), which may further contribute to our disparate observations of ozone enhancement and $\gamma \mathrm{T}$-mediated attenuation in mucin gene and protein expression.

In summary, we describe for the first time an animal model of experimental allergic sinusitis, as well as the unique interaction between two disparate stimuli, an airborne 
toxicant and an allergen, to produce inflammation and mucous cell metaplasia in nasal and paranasal airways. We have furthermore described the therapeutic effects of $\gamma \mathrm{T}$, an isoform of vitamin $\mathrm{E}$ with broad and novel anti-inflammatory properties that attenuate the effects of ozone in allergic upper airways. These findings in a rodent model warrant further investigation in clinical studies to determine the safety and efficacy of $\gamma \mathrm{T}$ supplements against allergic rhinosinusitis and exacerbations by environmental triggers such as ozone.

\section{Acknowledgments}

Funding

This work was supported by National Institutes of Health NCCAM: P01 AT002620.

\section{References}

Adler KB, Fischer BM, Li H, Choe NH, Wright DT. Hypersecretion of mucin in response to inflammatory mediators by guinea pig tracheal epithelial cells in vitro is blocked by inhibition of nitric oxide synthase. Am J Respir Cell Mol Biol. 1995; 13:526-530. [PubMed: 7576687]

Calderon-Garciduenas L, Wen-Wang L, Zhang YJ, Rodriguez-Alcaraz A, Osnaya N, VillarrealCalderon A, Santella RM. 8-hydroxy-2'-deoxyguanosine, a major mutagenic oxidative DNA lesion, and DNA strand breaks in nasal respiratory epithelium of children exposed to urban pollution. Environ Health Perspect. 1999; 107:469-474. [PubMed: 10339447]

Cho HY, Hotchkiss JA, Harkema JR. Inflammatory and epithelial responses during the development of ozone-induced mucous cell metaplasia in the nasal epithelium of rats. Toxicol Sci. 1999; 51:135145. [PubMed: 10496685]

Christen S, Woodall AA, Shigenaga MK, Southwell-Keely PT, Duncan MW, Ames BN. gammatocopherol traps muta-genic electrophiles such as $\mathrm{NO}(\mathrm{X})$ and complements alpha-tocopherol: Physiological implications. Proc Natl Acad Sci U S A. 1997; 94:3217-3222. [PubMed: 9096373]

Cooney RV, Franke AA, Harwood PJ, Hatch-Pigott V, Custer LJ, Mordan LJ. Gamma-tocopherol detoxification of nitrogen dioxide: Superiority to alpha-tocopherol. Proc Natl Acad Sci U S A. 1993; 90:1771-1775. [PubMed: 8446589]

Fischer BM, Voynow JA. Neutrophil elastase induces MUC5AC gene expression in airway epithelium via a pathway involving reactive oxygen species. Am J Respir Cell Mol Biol. 2002; 26:447-452. [PubMed: 11919081]

Fortoul TI, Valverde M, Lopez Mdel C, Lopez I, Sanchez I, Avila-Costa MR, Avila-Casado Mdel C, Mussali-Galante P, Soria E, Rojas E. Nasal cytology and genotoxic damage in nasal epithelium and leukocytes: Asthmatics versus nonasthmatics. Int Arch Allergy Immunol. 2003; 130:232-235. [PubMed: 12660428]

Fukushima A, Ozaki A, Fukata K, Ueno H. Differential expression and signaling of IFN-gamma in the conjunctiva between Lewis and Brown Norway rats. Microbiol Immunol. 2003; 47:785-796. [PubMed: 14605445]

Gent JF, Triche EW, Holford TR, Belanger K, Bracken MB, Beckett WS, Leaderer BP. Association of low-level ozone and fine particles with respiratory symptoms in children with asthma. JAMA. 2003; 290:1859-1867. [PubMed: 14532314]

Harkema JR, Hotchkiss JA, Griffith WC. Mucous cell metaplasia in rat nasal epithelium after a 20month exposure to ozone: A morphometric study of epithelial differentiation. Am J Respir Cell Mol Biol. 1997; 16:521-530. [PubMed: 9160834]

Harkema JR, Hotchkiss JA, Henderson RF. Effects of 0.12 and 0.80 ppm ozone on rat nasal and nasopharyngeal epithelial mucosub-stances: Quantitative histochemistry. Toxicol Pathol. 1989; 17:525-535. [PubMed: 2814228]

Harkema JR, Plopper CG, Hyde DM, St George JA. Regional differences in quantities of histochemically detectable mucosubstances in nasal, paranasal, and nasopharyngeal epithelium of the bonnet monkey. J Histochem Cytochem. 1987; 35:279-286. [PubMed: 2434556] 
Hiltermann TJ, de Bruijne CR, Stolk J, Zwinderman AH, Spieksma FT, Roemer W, Steerenberg PA, Fischer PH, van Bree L, Hiemstra PS. Effects of photochemical air pollution and allergen exposure on upper respiratory tract inflammation in asthmatics. Am J Respir Crit Care Med. 1997; 156:1765-1772. [PubMed: 9412553]

Jang AS, Choi IS, Yang SY, Kim YG, Lee JH, Park SW, Park CS. Antioxidant responsiveness in BALB/c mice exposed to ozone. Respiration. 2005; 72:79-84. [PubMed: 15753639]

Jiang Q, Ames BN. Gamma-tocopherol, but not alpha-tocopherol, decreases proinflammatory eicosanoids and inflammation damage in rats. FASEB J. 2003; 17:816-822. [PubMed: 12724340]

Jiang Q, Christen S, Shigenaga MK, Ames BN. gamma-tocopherol, the major form of vitamin E in the US diet, deserves more attention. Am J Clin Nutr. 2001; 74:714-722. [PubMed: 11722951]

Jiang Q, Elson-Schwab I, Courtemanche C, Ames BN. Gamma-tocopherol and its major metabolite, in contrast to alpha-tocopherol, inhibit cyclooxygenase activity in macrophages and epithelial cells. Proc Natl Acad Sci U S A. 2000; 97:11494-11499. [PubMed: 11005841]

Kari F, Hatch G, Slade R, Crissman K, Simeonova PP, Luster M. Dietary restriction mitigates ozoneinduced lung inflammation in rats: A role for endogenous antioxidants. Am J Respir Cell Mol Biol. 1997; 17:740-747. [PubMed: 9409561]

Kelly FJ, Mudway I, Blomberg A, Frew A, Sandstrom T. Altered lung antioxidan status in patients with mild asthma. Lancet. 1999; 354:482-483. [PubMed: 10465176]

Ko FW, Tam W, Wong TW, Lai CK, Wong GW, Leung TF, Ng SS, Hui DS. Effects of air pollution on asthma hospitalization rates in different age groups in Hong Kong. Clin Exp Allergy. 2007; 37:1312-1319. [PubMed: 17845411]

Kompauer I, Heinrich J, Wolfram G, Linseisen J. Association of carotenoids, tocopherols and vitamin $\mathrm{C}$ in plasma with allergic rhinitis and allergic sensitisation in adults. Public Health Nutr. 2006; 9:472-479. [PubMed: 16870019]

Kongerud J, Crissman K, Hatch G, Alexis N. Ascorbic acid is decreased in induced sputum of mild asthmatics. Inhal Toxicol. 2003; 15:101-109. [PubMed: 12528041]

Kopp MV, Ulmer C, Ihorst G, Seydewitz HH, Frischer T, Forster J, Kuehr J. Upper airway inflammation in children exposed to ambient ozone and potential signs of adaptation. Eur Respir J. 1999; 14:854-861. [PubMed: 10573233]

Mery S, Gross EA, Joyner DR, Godo M, Morgan KT. Nasal diagrams: A tool for recording the distribution of nasal lesions in rats and mice. Toxicol Pathol. 1994; 22:353-372. [PubMed: 7817125]

Millstein J, Gilliland F, Berhane K, Gauderman WJ, McConnell R, Avol E, Rappaport EB, Peters JM. Effects of ambient air pollutants on asthma medication use and wheezing among fourth-grade school children from 12 Southern California communities enrolled in The Children's Health Study. Arch Environ Health. 2004; 59:505-514. [PubMed: 16425660]

Mudway IS, Behndig AF, Helleday R, Pourazar J, Frew AJ, Kelly FJ, Blomberg A. Vitamin supplementation does not protect against symptoms in ozone-responsive subjects. Free Radic Biol Med. 2006; 40:1702-1712. [PubMed: 16767844]

Nikasinovic L, Momas I, Seta N. Nasal epithelial and inflammatory response to ozone exposure: A review of laboratory-based studies published since 1985. J Toxicol Environ Health B Crit Rev. 2003; 6:521-568. [PubMed: 12888446]

Ochs-Balcom HM, Grant BJ, Muti P, Sempos CT, Freudenheim JL, Browne RW, McCann SE, Trevisan M, Cassano PA, Iacoviello L, Schunemann HJ. Antioxidants, oxidative stress, and pulmonary function in individuals diagnosed with asthma or COPD. Eur J Clin Nutr. 2006; 60:991-999. [PubMed: 16482071]

Pearson PJ, Lewis SA, Britton J, Fogarty A. Vitamin E supplements in asthma: A parallel group randomised placebo controlled trial. Thorax. 2004; 59:652-656. [PubMed: 15282383]

Peden DB, Setzer RW Jr, Devlin RB. Ozone exposure has both a priming effect on allergen-induced responses and an intrinsic inflammatory action in the nasal airways of perennially allergic asthmatics. Am J Respir Crit Care Med. 1995; 151:1336-1345. [PubMed: 7735583]

Riediker M, Monn C, Koller T, Stahel WA, Wuthrich B. Air pollutants enhance rhinoconjunctivitis symptoms in pollen-allergic individuals. Ann Allergy Asthma Immunol. 2001; 87:311-318. [PubMed: 11686424] 
Samet JM, Hatch GE, Horstman D, Steck-Scott S, Arab L, Bromberg PA, Levine M, McDonnell WF, Devlin RB. Effect of antioxidant supplementation on ozone-induced lung injury in human subjects. Am J Respir Crit Care Med. 2001; 164:819-825. [PubMed: 11549539]

Sanchez-Carrillo CI, Ceron-Mireles P, Rojas-Martinez MR, Mendoza-Alvarado L, Olaiz-Fernandez G, Borja-Aburto VH. Surveillance of acute health effects of air pollution in Mexico City. Epidemiology. 2003; 14:536-544. [PubMed: 14501268]

Shahar E, Hassoun G, Pollack S. Effect of vitamin E supplementation on the regular treatment of seasonal allergic rhinitis. Ann Allergy Asthma Immunol. 2004; 92:654-658. [PubMed: 15237767]

Shao MX, Nadel JA. Neutrophil elastase induces MUC5AC mucin production in human airway epithelial cells via a cascade involving protein kinase $\mathrm{C}$, reactive oxygen species, and TNF-alphaconverting enzyme. J Immunol. 2005; 175:4009-4016. [PubMed: 16148149]

Shimizu T, Hirano H, Majima Y, Sakakura Y. A mechanism of antigen-induced mucus production in nasal epithelium of sensitized rats. A comparison with lipopolysaccharide-induced mucus production. Am J Respir Crit Care Med. 2000; 161:1648-1654. [PubMed: 10806170]

Sienra-Monge JJ, Ramirez-Aguilar M, Moreno-Macias H, Reyes-Ruiz NI, Del Rio-Navarro BE, RuizNavarro MX, Hatch G, Crissman K, Slade R, Devlin RB, Romieu I. Antioxidant supplementation and nasal inflammatory responses among young asthmatics exposed to high levels of ozone. Clin Exp Immunol. 2004; 138:317-322. [PubMed: 15498043]

Song JS, Kang CM, Yoo MB, Kim SJ, Yoon HK, Kim YK, Kim KH, Moon HS, Park SH. Nitric oxide induces MUC5AC mucin in respiratory epithelial cells through PKC and ERK dependent pathways. Respir Res. 2007; 8:28. [PubMed: 17391532]

Suchankova J, Voprsalova M, Kottova M, Semecky V, Visnovsky P. Effects of oral alpha-tocopherol on lung response in rat model of allergic asthma. Respirology. 2006; 11:414-421. [PubMed: 16771910]

Vargaftig BB, Singer M. Leukotrienes mediate murine bronch-opulmonary hyperreactivity, inflammation, and part of mucosal metaplasia and tissue injury induced by recombinant murine interleukin-13. Am J Respir Cell Mol Biol. 2003; 28:410-419. [PubMed: 12654629]

Wagner JG, Hotchkiss JA, Harkema JR. Effects of ozone and endotoxin coexposure on rat airway epithelium: potentiation of toxicant-induced alterations. Environ Health Perspect 109. 2001; (Suppl 4):591-598.

Wagner JG, Hotchkiss JA, Harkema JR. Enhancement of nasal inflammatory and epithelial responses after ozone and allergen coexposure in Brown Norway rats. Toxicol Sci. 2002; 67:284-294. [PubMed: 12011488]

Wagner JG, Jiang Q, Harkema JR, Ames BN, Illek B, Roubey RA, Peden DB. gamma-Tocopherol prevents airway eosinophi-lia and mucous cell hyperplasia in experimentally induced allergic rhinitis and asthma. Clin Exp Allergy. 2008; 38:501-511. [PubMed: 17970781]

Wagner JG, Jiang Q, Harkema JR, Illek B, Patel DD, Ames BN, Peden DB. Ozone enhancement of lower airway allergic inflammation is prevented by gamma-tocopherol. Free Radic Biol Med. 2007; 43:1176-1188. [PubMed: 17854713]

Wagner JG, Van Dyken SJ, Hotchkiss JA, Harkema JR. Endotoxin enhancement of ozone-induced mucous cell metaplasia is neu-trophil-dependent in rat nasal epithelium. Toxicol Sci. 2001; 60:338-347. [PubMed: 11248146]

Wiester MJ, Tepper JS, Winsett DW, Crissman KM, Richards JH, Costa DL. Adaptation to ozone in rats and its association with ascorbic acid in the lung. Fundam Appl Toxicol. 1996; 31:56-64. [PubMed: 8998953]

Wolf G. gamma-Tocopherol: An efficient protector of lipids against nitric oxide-initiated peroxidative damage. Nutr Rev. 1997; 55:376-378. [PubMed: 9354084] 


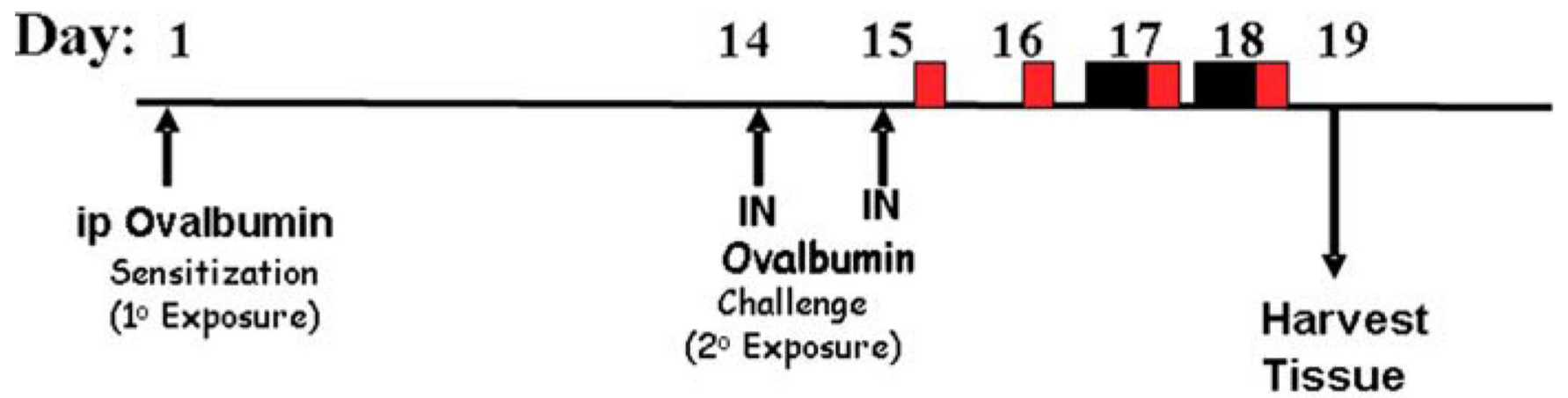

\section{$=0$ or $1 \mathrm{ppm}$ Ozone, $8 \mathrm{~h}(7: 00 \mathrm{AM}-3: 00 \mathrm{PM})$}

\section{$=0$ or $100 \mathrm{mg} / \mathrm{kg} \gamma \mathrm{T}$, p.o., 6:00PM}

Figure 1.

Experimental protocols. Rats were sensitized to OVA by intraperitoneal injection (ip) and two weeks later were challenged for two consecutive days by intranasal instillation (IN). Daily supplementation with $\gamma$-tocopherol (red box) started after the last challenge and continued to the duration of the study. Ozone exposures (black box) were conducted for two consecutive days prior to necropsy. 


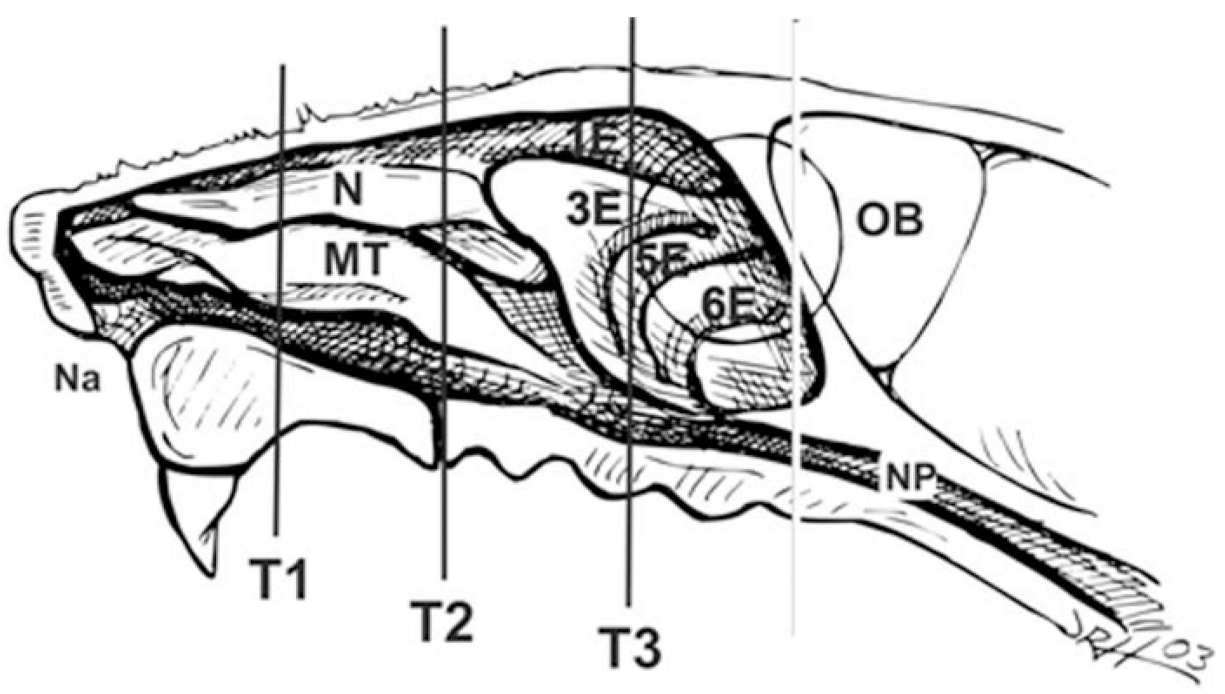

T1

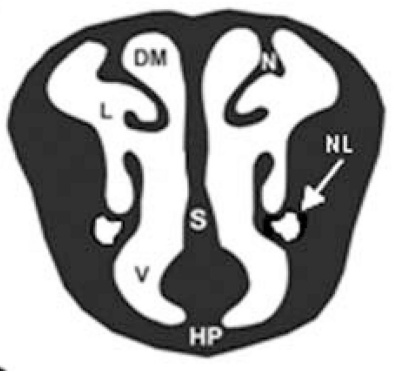

T3

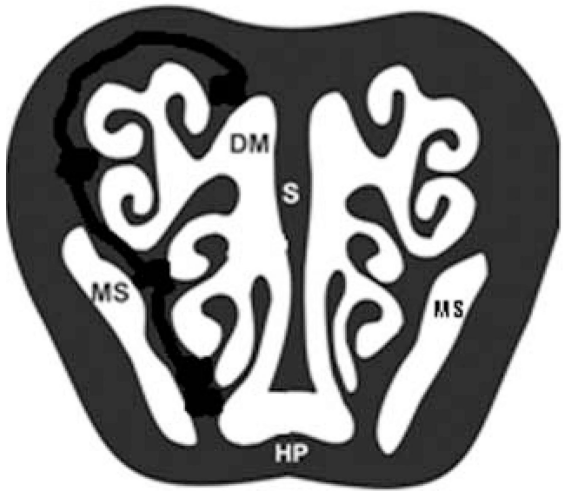

T2

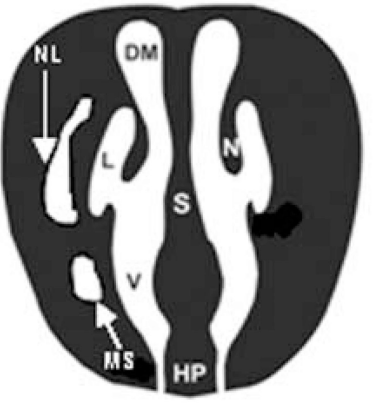

Figure 2.

Nasal sites of analysis. Three specific nasal profiles, T1, T2, and T3, were analyzed by morphometric and histological techniques. The nasal profile $\mathrm{T} 1$ is at the level immediately posterior to the upper incisors, $\mathrm{T} 2$ is at the incisive papilla, and $\mathrm{T} 3$ is at the second palatine ridge. $\mathrm{Na}=$ naris; $\mathrm{N}=$ nasoturbinate; $\mathrm{MT}=$ maxilloturbinate $; 1-6 \mathrm{E}=$ ethmoids; $\mathrm{NP}=$ nasopharynx; $\mathrm{L}=$ lateral wall; $\mathrm{DM}=$ dorsal meatus; $\mathrm{V}=$ ventral wall; $\mathrm{S}=$ septum; $\mathrm{HP}=$ hard palate; $\mathrm{NL}=$ naso-lacrimal duct; $\mathrm{MS}=$ maxillary sinus. 

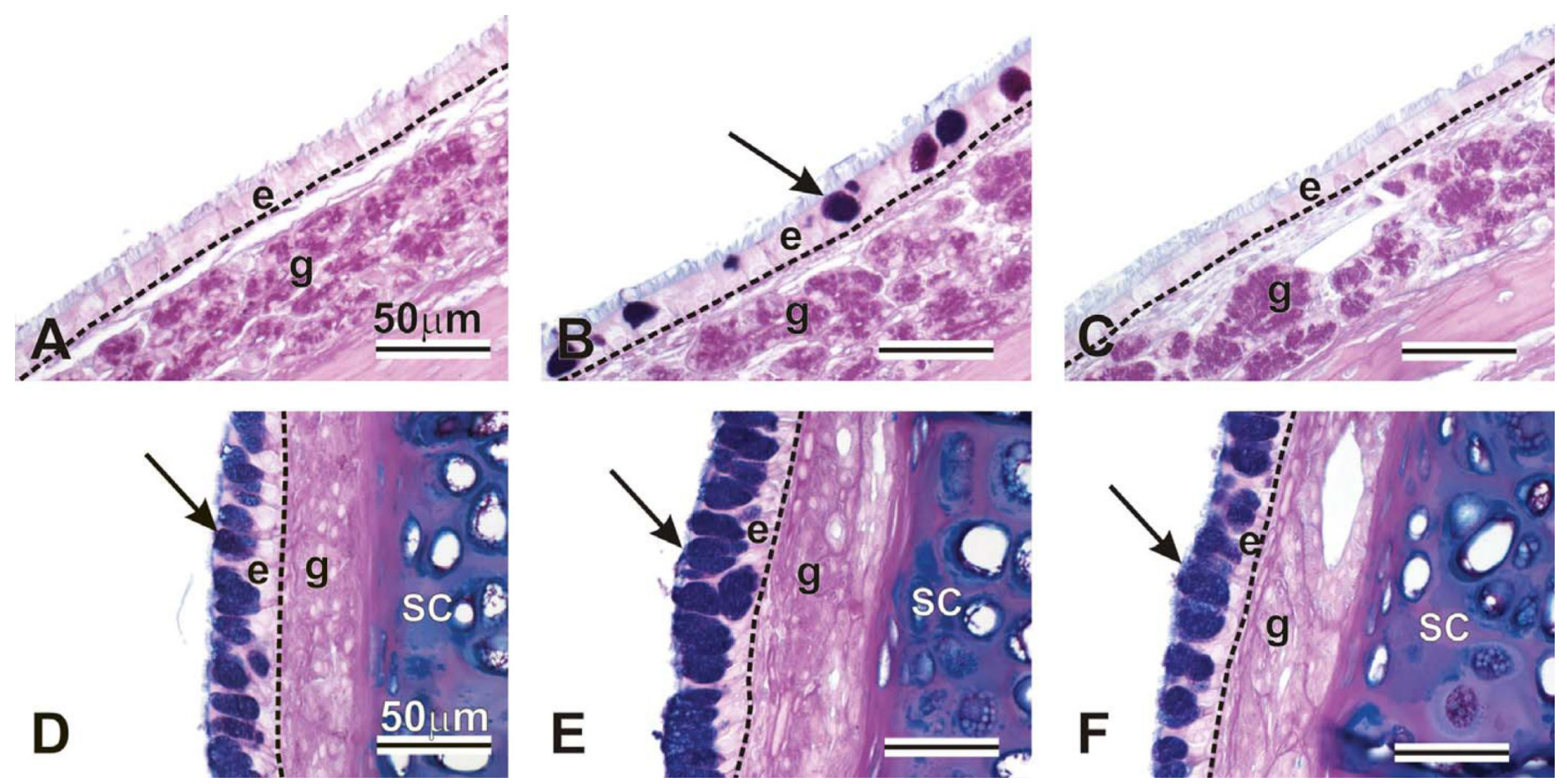

Figure 3.

Intraepithelial mucosubstances in the maxillary sinus (A, B, C) and nasal septum (D, E, F). Animals were challenged with saline and exposed to filtered air (A, D), challenged with ovalbumin, exposed to ozone, and treated with 0 (B, E) or $100 \mathrm{mg} / \mathrm{kg}$ g-tocopherol (C, F). Tissues were stained with AB/PAS to detect intraepithelial mucosubstances (arrows). e = epithelium; $\mathrm{g}=$ gland; $\mathrm{sc}=$ septal cartilage. 


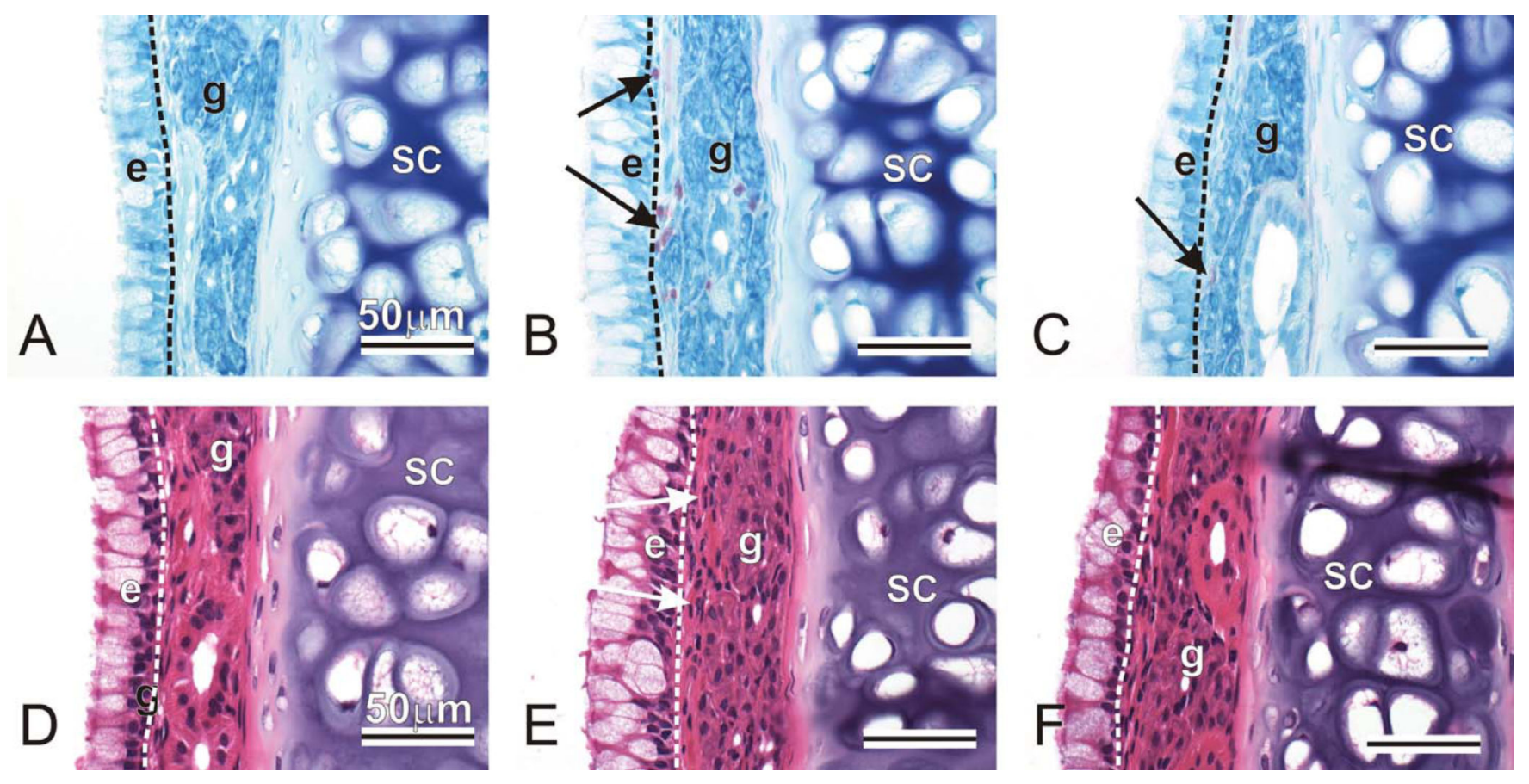

Figure 4.

Mucosal eosinophils in nasal mid-septum. Animals were challenged with saline and exposed to filtered air (AD), challenged with ovalbumin, exposed to ozone, and treated with 0 (BE) or $100 \mathrm{mg} / \mathrm{kg} \gamma$-tocopherol (CF). Tissues were stained with May-Grunwald (ABC) to detect eosinophils (arrows, pink-stained cells), or with hematoxylin and eosin (DEF). e = epithelium; $\mathrm{g}=$ gland; $\mathrm{sc}=$ septal cartilage. 

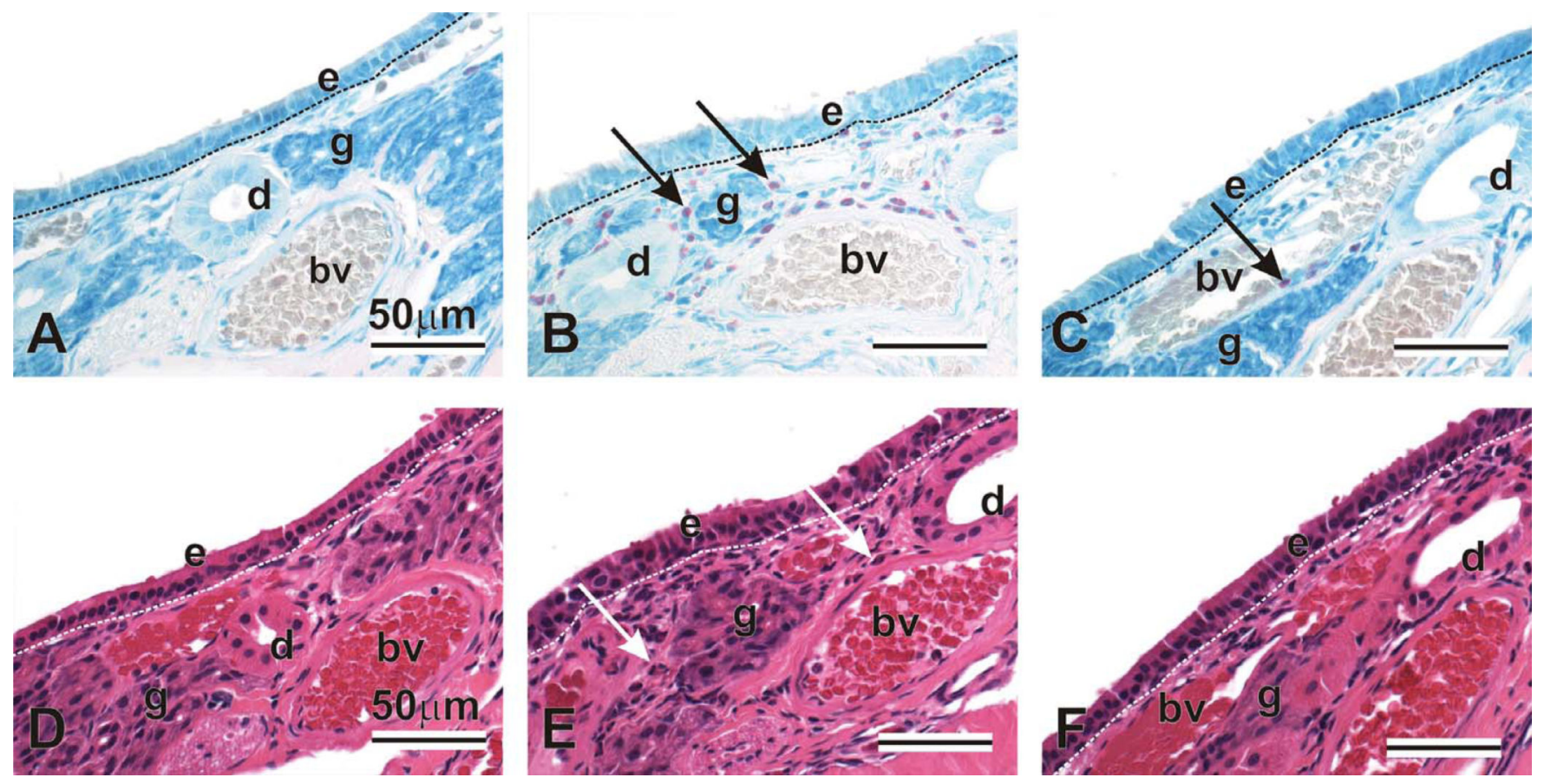

Figure 5.

Mucosal eosinophils in nasal lateral wall. Animals were challenged with saline and exposed to filtered air (AD), challenged with ovalbumin, exposed to ozone, and treated with 0 (BE) or $100 \mathrm{mg} / \mathrm{kg} \gamma$-tocopherol (CF). Tissues were stained with May-Grunwald (ABC) to detect eosinophils (arrows, pink-stained cells), or with hematoxylin and eosin (DEF). e = epithelium; $\mathrm{d}=$ duct; $\mathrm{g}=$ gland; $\mathrm{bv}=$ blood vessel. 

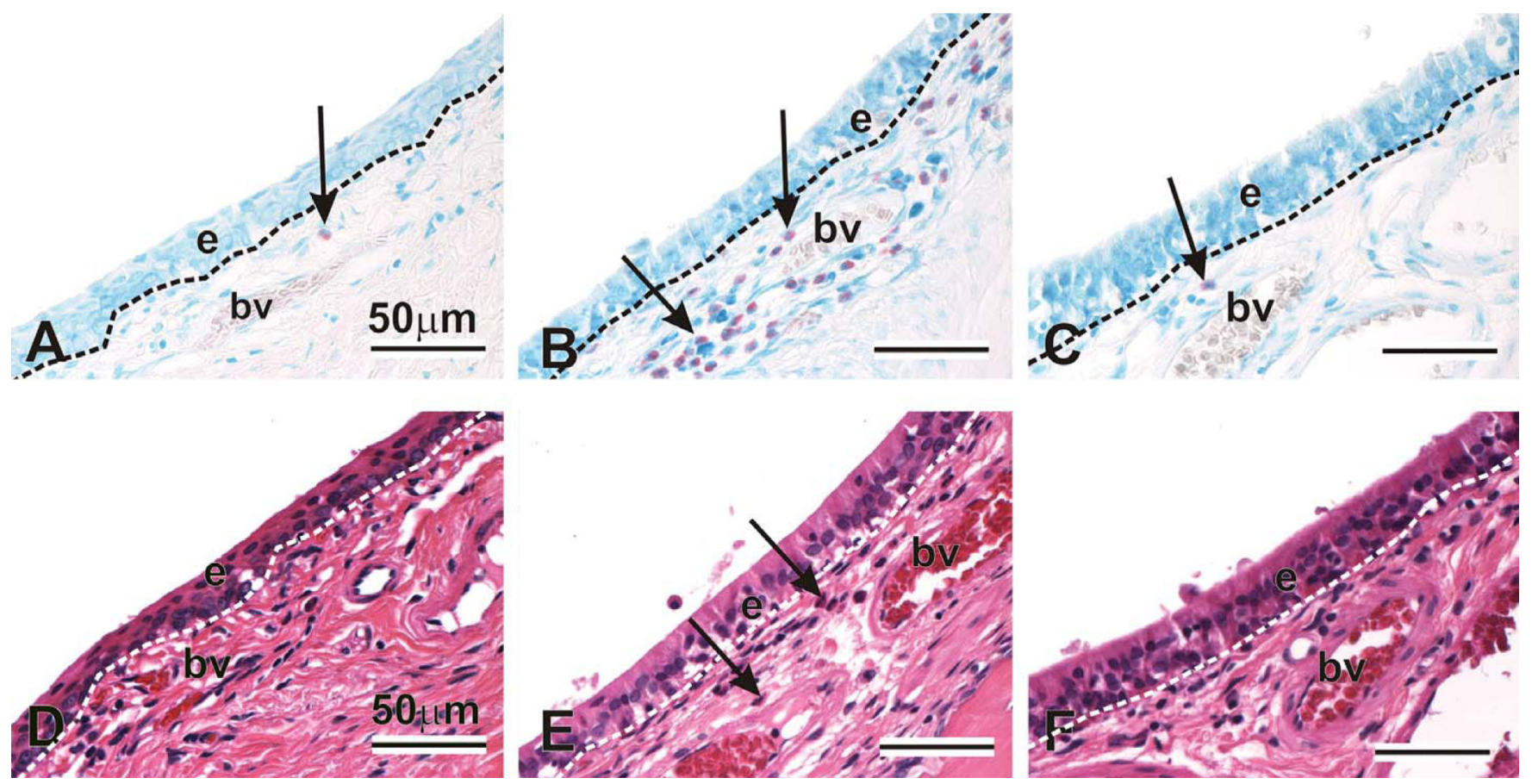

Figure 6.

Periductal eosinophils in the nasolacrimal duct. Animals were challenged with saline and exposed to filtered air (AD), challenged with ovalbumin, exposed to ozone, and treated with 0 (BE) or $100 \mathrm{mg} / \mathrm{kg} \gamma$-tocopherol (CF). Tissues were stained with May-Grunwald (ABC) to detect eosinophils (arrows, pink-stained cells), or with hematoxylin and eosin (DEF). e = epithelium; bv = blood vessel. 

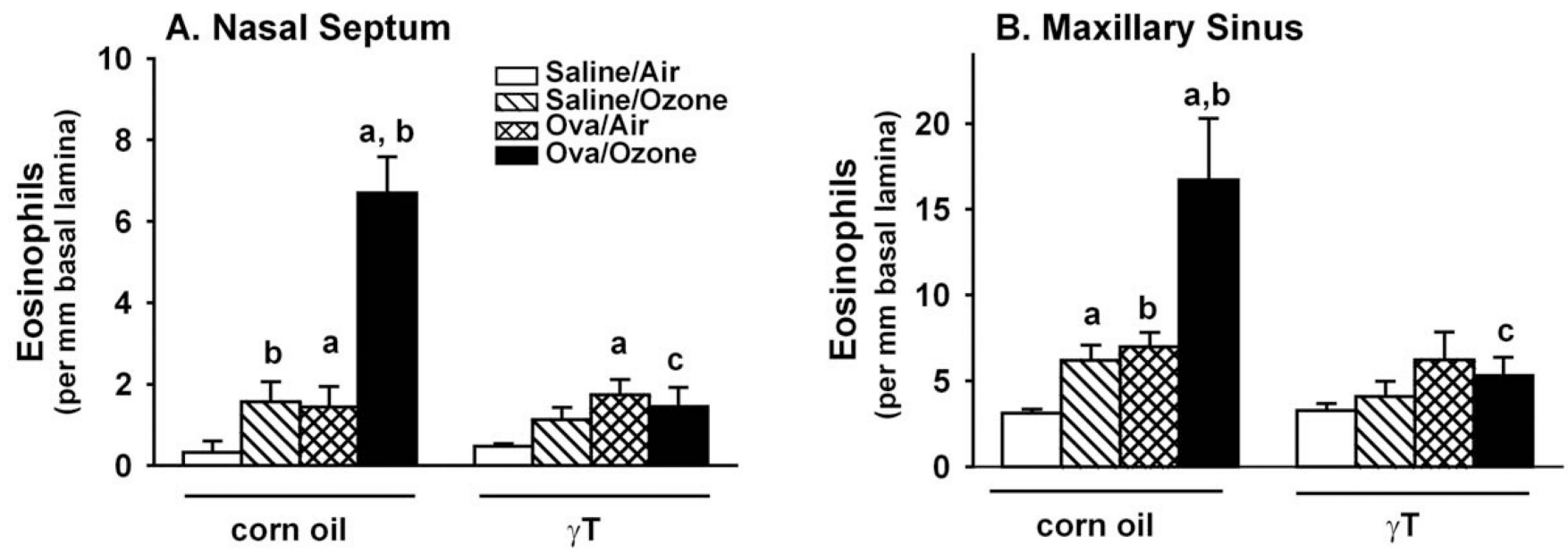

\section{Proximal Nasolacrimal Duct}
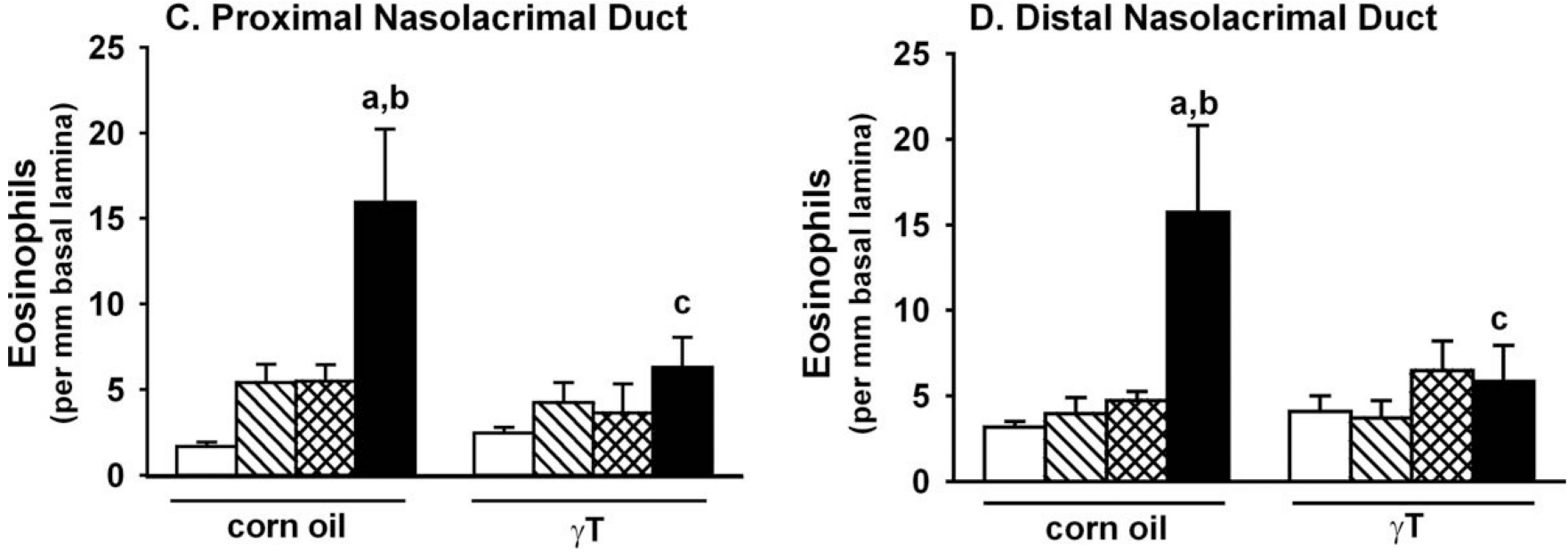

Figure 7.

Mucosal eosinophils in the midseptum (A), maxillary sinus (B), and the proximal and distal nasolacrimal ducts (C and D, respectively). Nasal sections were collected and stained with May-Grunwald, and site-selective morphometry of tissue eosinophils was conducted as described in the Methods section. $n=7 ; \mathrm{a}=$ significantly different from respective group challenged with saline; $b=$ significantly different from respective group exposed to filtered air; $\mathrm{c}=$ significantly different from respective group treated with $0 \mathrm{mg} / \mathrm{kg} \gamma \mathrm{T}$ (corn oil). $p<$. 05 . 
A. Nasal Septum

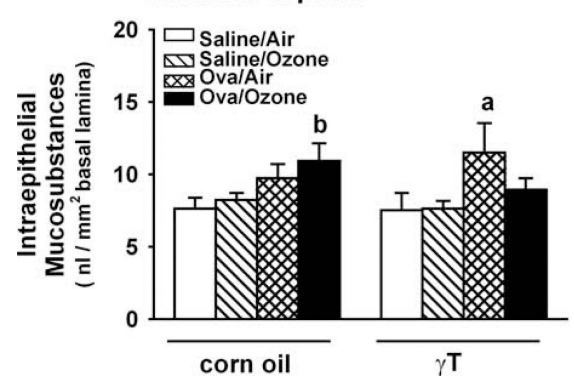

B. Proximal Maxillary Sinus

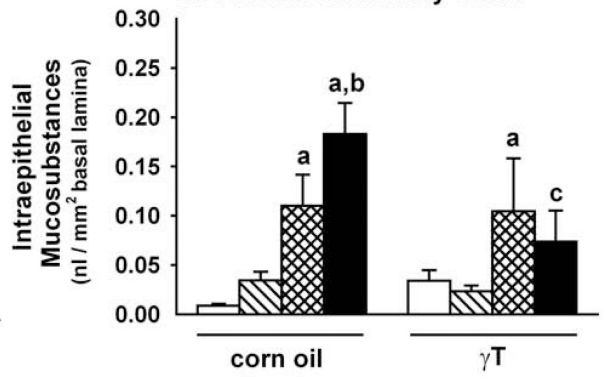

C. Distal Maxillary Sinus

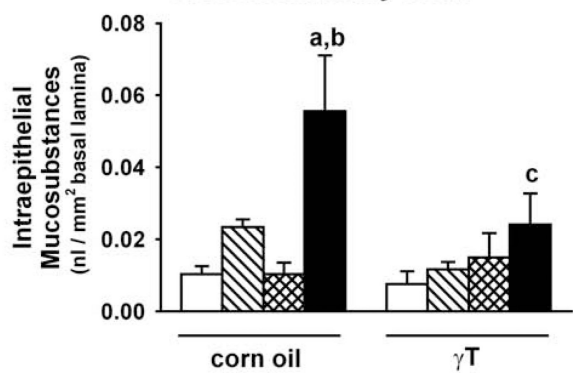

Figure 8.

Intraepithelial mucosubstances in the midseptum (A), and the proximal and distal maxillary sinuses (B and C, respectively). Nasal sections were collected and stained with AB/PAS, and site-selective morphometric evaluation of mucosubstances was conducted as described in the Methods section. $n=7$; a = significantly different from respective group challenged with saline; $\mathrm{b}=$ significantly different from respective group exposed to filtered air; $\mathrm{c}=$ significantly different from respective group treated with $0 \mathrm{mg} / \mathrm{kg} \gamma \mathrm{T}$ (corn oil). $p<.05$. 


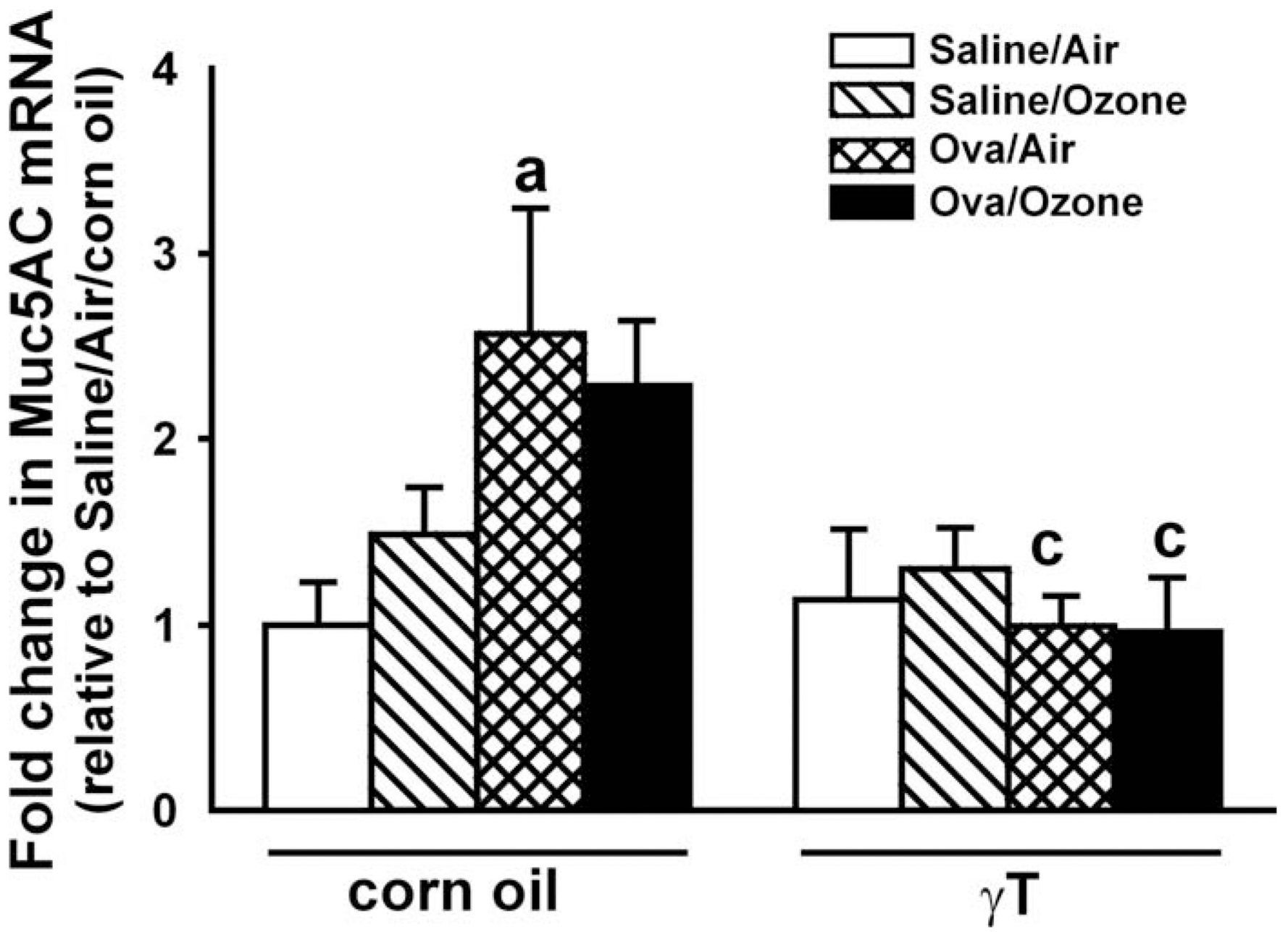

Figure 9.

Mucin 5AC mRNA in the nasal septum. Mucosa was microdissected from the nasal septum, and RNA was isolated and processed by reverse transcriptase polymerase chain reaction, as described in the Methods section. $n=7 ; \mathrm{a}=$ significantly different from respective group challenged with saline; $\mathrm{c}=$ significantly different from respective group treated with 0 $\mathrm{mg} / \mathrm{kg} \gamma \mathrm{T}$ (corn oil). $p<.05$. 


\section{Table 1}

Plasma tocopherol content in from rats exposed to air or ozone, challenged with saline or ovalbumin (OVA), with and without supplementation with $\gamma$-tocopherol.

\begin{tabular}{lcr}
\hline & \multicolumn{2}{c}{ Plasma tocopherols $(\boldsymbol{\mu M})$} \\
\cline { 2 - 3 } Experimental groups & $\gamma$-tocopherol & a-tocopherol \\
\hline Saline/air & $0.35 \pm 0.04$ & $10.00 \pm 1.27$ \\
Saline/ozone & $0.41 \pm 0.07$ & $11.10 \pm 1.25$ \\
OVA/air & $0.27 \pm 0.06$ & $7.03 \pm 1.55$ \\
OVA/ozone & $0.35 \pm 0.04$ & $7.70 \pm 1.26$ \\
Saline/air/ $\gamma$-tocopherol & $1.64 \pm 0.23^{b}$ & $9.87 \pm 0.41$ \\
Saline/ozone/ $\gamma$-tocopherol & $2.25 \pm 0.39^{b}$ & $8.68 \pm 1.10$ \\
OVA/air/ $\gamma$-tocopherol & $2.25 \pm 0.24^{b}$ & $6.00 \pm 1.36^{a}$ \\
OVA/ozone/ $\gamma$-tocopherol & $2.02 \pm 0.54^{b}$ & $8.70 \pm 0.58$ \\
\hline
\end{tabular}

Note: Data are expressed as mean \pm standard error of the mean.

${ }^{a}$ Significantly different from respective group challenged with OVA.

${ }^{b}$ Significantly different from respective group without $\gamma$-tocopherol supplementation.

$p<05$. 